Supplemental Information for

\title{
Evaluation of a new Aerosol Chemical Speciation Monitor (ACSM) system at an urban site in Atlanta, GA: the use of capture vaporizer and $\mathbf{P M}_{2.5}$ inlet
}

Taekyu Joo $^{\mathrm{a}}$, Yunle Chen ${ }^{\mathrm{a}, 1}$, Weiqi Xu ${ }^{\mathrm{b}, \mathrm{c}, \mathrm{d}}$, Philip Croteau ${ }^{\mathrm{e}}$, Manjula R. Canagaratna ${ }^{\mathrm{e}}$, Dong Gao ${ }^{\mathrm{f}, 2}$,

5 Hongyu Guo ${ }^{\mathrm{a}, 3,4}$, Gabriela Saavedra ${ }^{\mathrm{a}}$, Seong Shik Kim ${ }^{\mathrm{d}, 5}$, Yele Sun ${ }^{\mathrm{b}, \mathrm{c}}$, Rodney Weber ${ }^{\mathrm{a}}$, John Jayne , Nga Lee $\mathrm{Ng}^{\mathrm{a}, \mathrm{d}, \mathrm{f} *}$

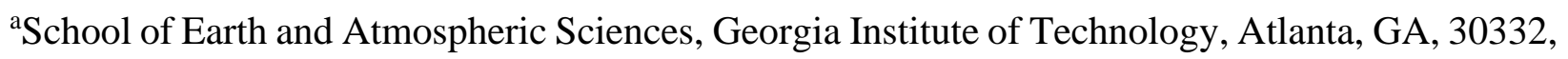
United States

$10{ }^{b}$ State Key Laboratory of Atmospheric Boundary Layer Physics and Atmospheric Chemistry, Institute of Atmospheric Physics, Chinese Academy of Sciences, Beijing 100029, China,

${ }^{\mathrm{c}}$ College of Earth Sciences, University of Chinese Academy of Sciences, Beijing 100049, China

${ }^{\mathrm{d}}$ School of Chemical and Biomolecular Engineering, Georgia Institute of Technology, Atlanta, GA, 30332, United States

15 e Aerodyne Research Inc., Billerica, MA, 01821, United States

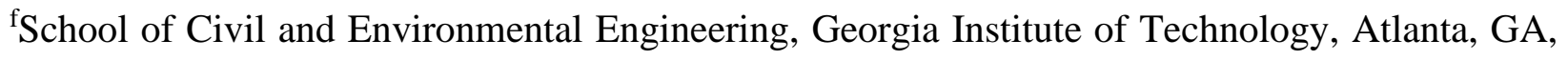
30332, United States

${ }^{1}$ Now at: Department of Public Health Sciences, University of Rochester School of Medicine and Dentistry, Rochester, NY 14642, United States

$20{ }^{2}$ Now at: School of Public Health, Yale University, New Haven, CT, 06511, United States

${ }^{3}$ Now at: Department of Chemistry, University of Colorado Boulder, Boulder, CO, 80309, United States 
${ }^{4}$ Now at: Cooperative Institute for Research in Environmental Sciences, University of Colorado Boulder, Boulder, CO, 80309, United States

$25{ }^{5}$ Now at: Division of Chemistry and Chemical Engineering, California Institute of Technology, Pasadena, CA, 91125, United States 


\section{S1. The selection of optimal PMF solution for SV-AMS and CV-ACSM}

The selection of optimal PMF solution for SV-AMS was processed based on the procedure in Zhang et al. ${ }^{1}$ The same type and number of factors are resolved as in previous studies (5 factors). ${ }^{2}$, ${ }^{3}$ AMS PMF solutions with a lower number of factors resolved the following: HOA and OOA from

35 2-factor solution; HOA, BBOA, and OOA from 3-factor solution; HOA, BBOA, LO-OOA, and MO-OOA from 4-factor solution. For additional number of factors, a pump factor (a factor characterized by prominent m/z $69\left(\mathrm{CF}_{3}^{+}\right)$and $\left.119\left(\mathrm{C}_{2} \mathrm{~F}_{5}{ }^{+}\right)\right)$was resolved from 6-factor solution. 7-factor solution split MO-OOA time series, 8-factor solution splits LO-OOA mass spectra, without showing a new meaningful factor. FPEAK $=0$ was chosen where $\mathrm{Q} / \mathrm{Q}_{\mathrm{exp}}$ was the lowest 40 (Figure S1a).

ACSM 5-factor solution corresponded to each factor resolved from AMS 5-factor solution. 2factor solution resolved HOA and OOA. 3-factor resolved HOA, LO-OOA, and MO-OOA. 4factor solution resolved HOA, BBOA, LO-OOA, and MO-OOA. 6-factor solution split HOA mass spectra, but the new factor did not show good correlation with any AMS PMF factor. 7-factor

45 solution resolved a factor with prominent $\mathrm{m} / \mathrm{z} 69$. 8-factor solution split mass spectra of the HOArelated factors that were resolved in the 6-factor solution, with prominent signal at $\mathrm{m} / \mathrm{z} 67,81$, and 95. FPEAK $=0$ was chosen as $Q / Q_{\exp }$ was the lowest and the correlation with each AMS PMF factor was the highest (Figure S1b). 


\section{S2. CV-ACSM error interpolation}

50 PMF analysis requires an error matrix as input. As the automatic error calculation for ACSM data reported errors that were an order of magnitude lower than expected in some periods for $\mathrm{m} / \mathrm{z}$ $59,67,70,71,72,80,82,83,90,93,94,95$, and 96 , we obtained the errors by interpolation, instead of using the default values which were lower than $5 \times 10^{-4}$ (Figure S2). Dips in the error time series did not appear to have a trend (i.e., the lower errors of each mass appeared at different times and

55 with different frequency). Among the listed masses, $m / z, 80,94,95$, and 96 show continuously low values of errors from the automatic error calculation while others show low error points occasionally. 

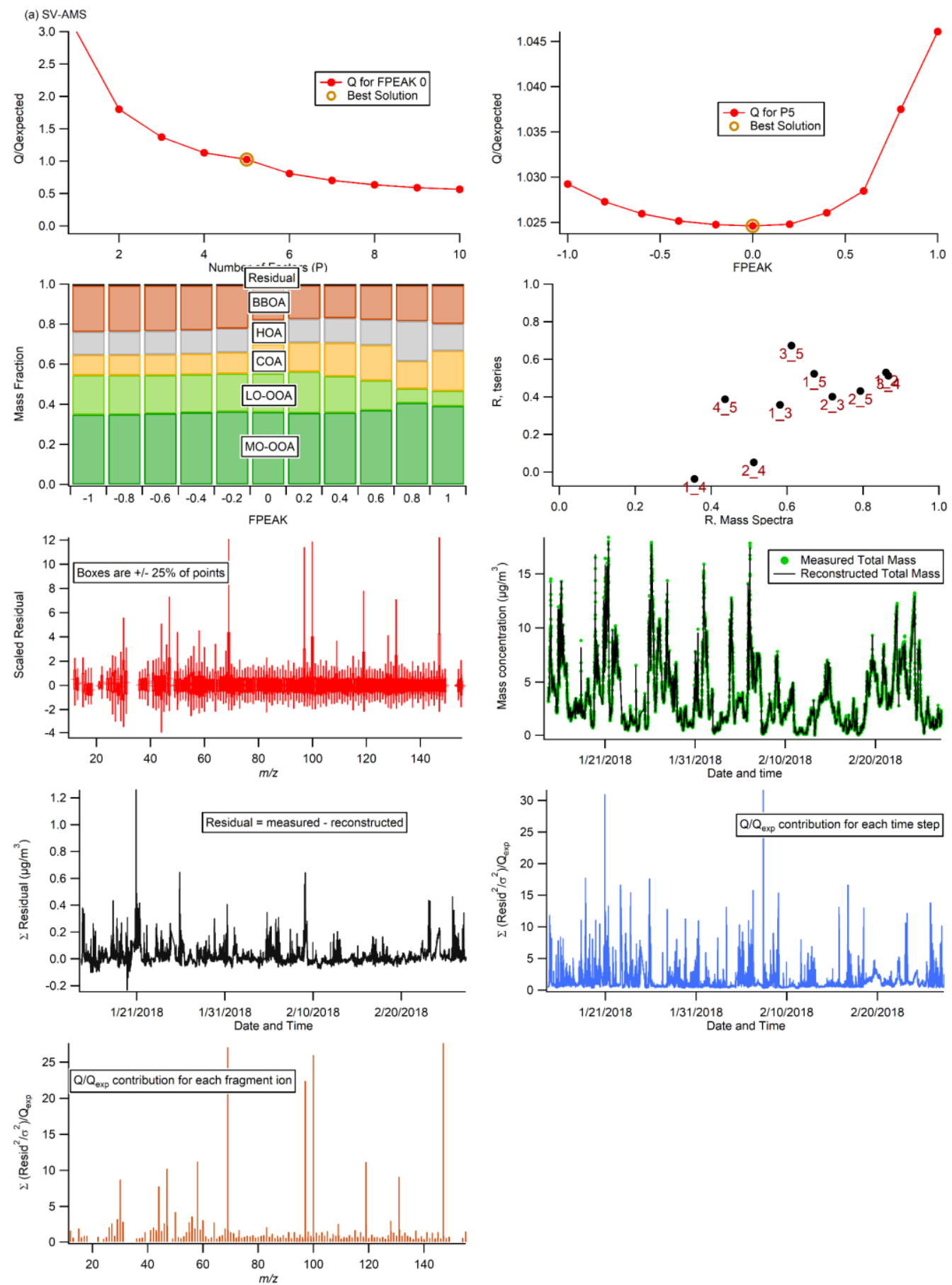

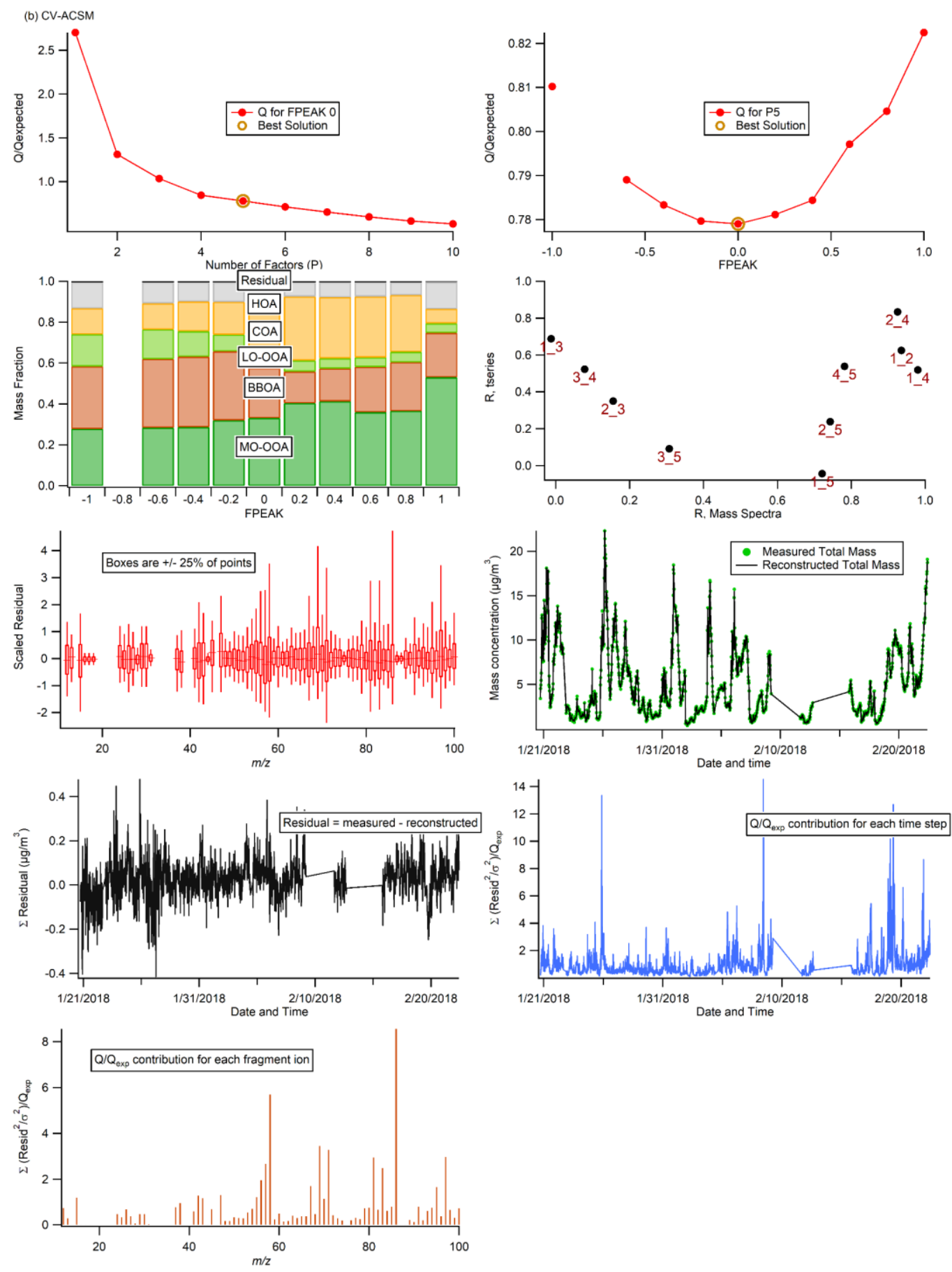

Figure S1. Diagnostic plots of PMF analysis of (a) SV-AMS and (b) CV-ACSM organics data. The following plots are shown for both a and b: (1) Q/Q $\mathrm{Q}_{\exp }$ vs. number of factors; (2) Q/Q $\mathrm{Q}_{\text {exp }}$ vs. FPEAK for the optimal number of factors solution; (3) mass fraction of PMF factors vs. FPEAK; (4) correlations of time series and mass spectra among PMF factors; (5) distribution of scaled residuals for each $\mathrm{m} / \mathrm{z}$; (6) time series of the measured and reconstructed OA mass; (7) time series of residual (= measured - reconstructed) of the least-square-fit vs. time; (8) time series of $\mathrm{Q} / \mathrm{Q}_{\exp }$; (9) $\mathrm{Q} / \mathrm{Q}_{\exp }$ values vs. $m / z$. 

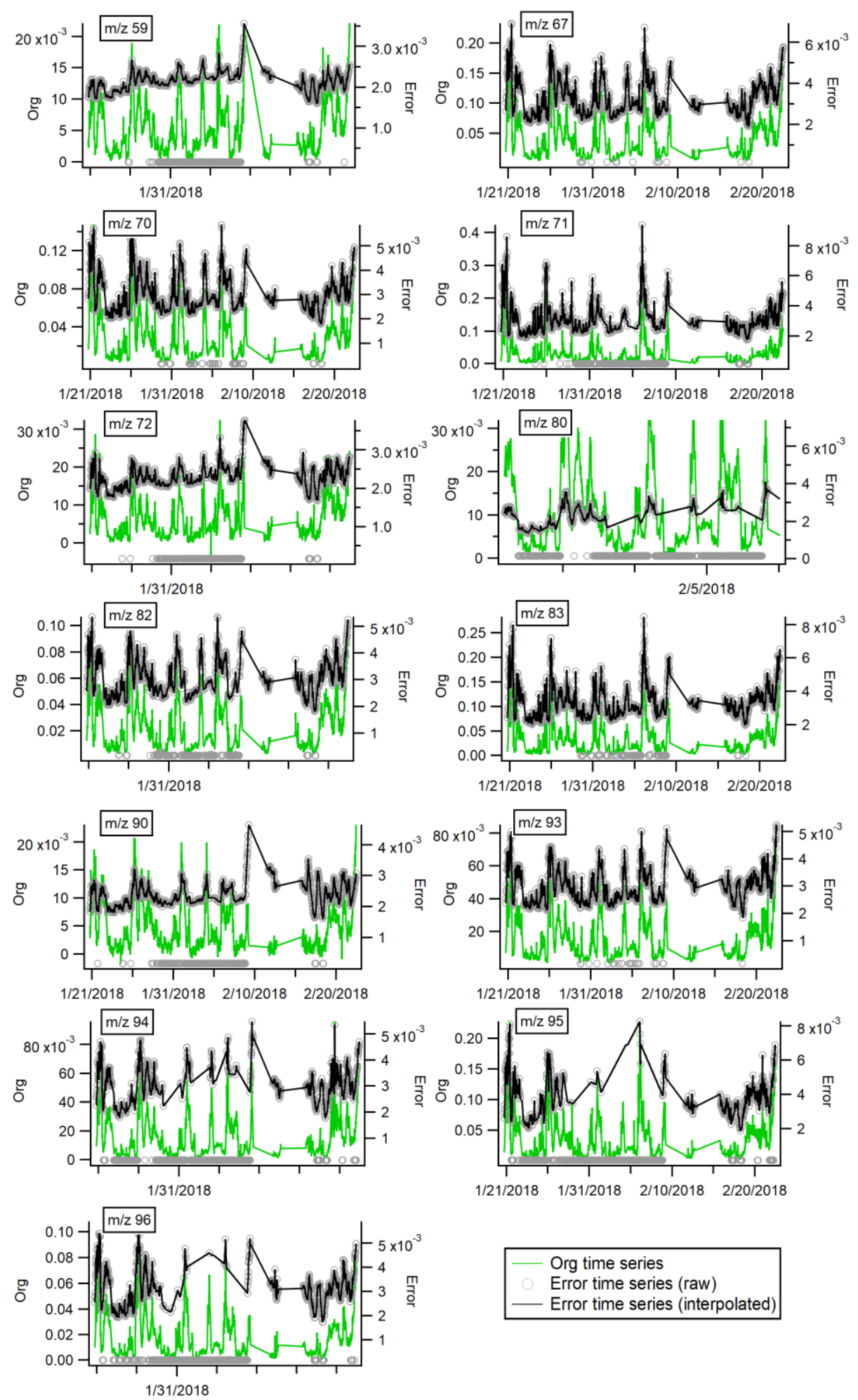

Figure S2. ACSM organic error interpolation of $m / z$ 59, 67, 70, 71, 72, 80, 82, 83, 90, 93, 94, 95, and 96. 


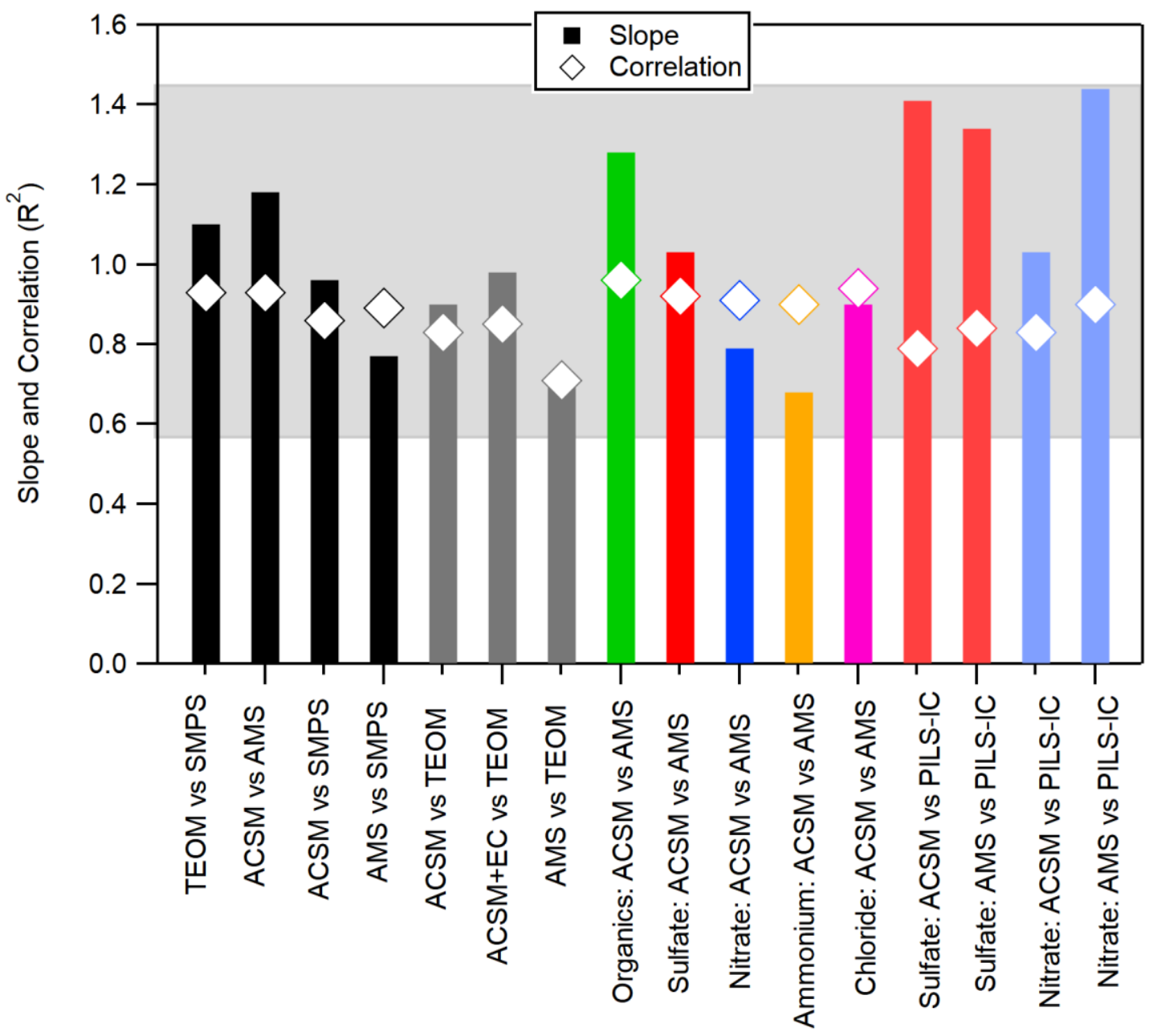

Figure S3. Comparisons of total (sum of refractory and non-refractory) mass concentration and concentration of each non-refractory species measured by $\mathrm{PM}_{2.5}-\mathrm{CV}-\mathrm{ACSM}, \mathrm{PM}_{1}-\mathrm{SV}$-AMS, and other colocated instruments (TEOM: PM$_{2.5}$ mass concentration, SMPS: PM 1 mass concentration, PILS-IC: PM inorganics). Grey region corresponds to the reported uncertainty of AMS and ACSM measurements. ${ }^{4,5}$ 
(a)
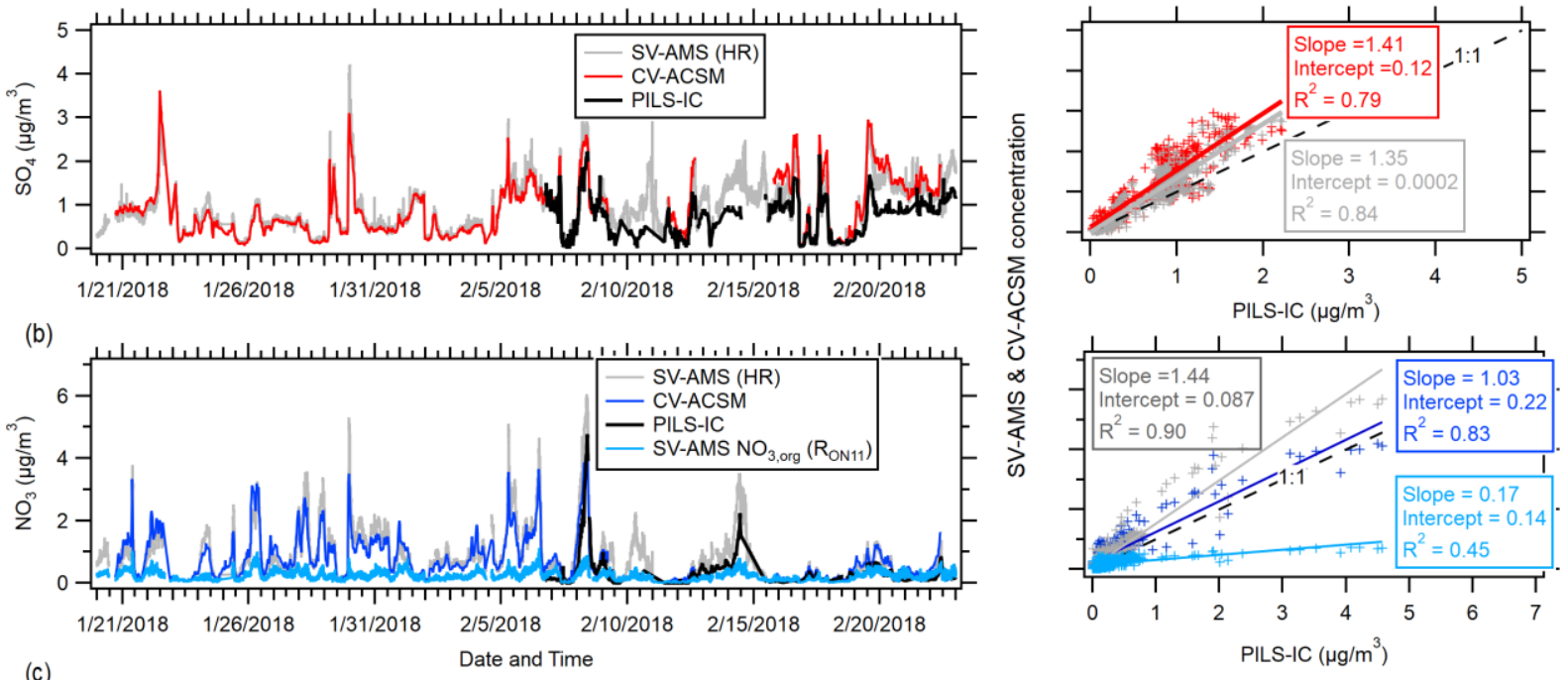

(c)

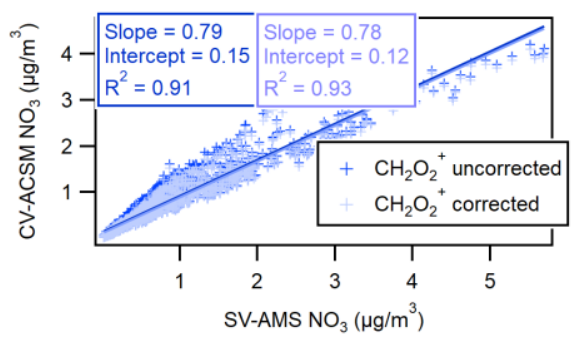

Figure S4. Time series and scatter plot comparison of (a) sulfate and (b) nitrate measured by CV-ACSM, SV-AMS, and PILS-IC. The AMS organic nitrate $\left(\mathrm{NO}_{3, \text { Org }}\right)$ was calculated based on the $\mathrm{NO}_{\mathrm{x}}{ }^{+}\left(\mathrm{NO}^{+} / \mathrm{NO}_{2}{ }^{+}\right)$ ratio of ratio method, where $\mathrm{NO}^{+} / \mathrm{NO}_{2}{ }^{+}$of organic nitrate $\left(\mathrm{R}_{\mathrm{ON}}\right)$ is estimated to be 11 (upper limit) from multiplying $\mathrm{R}_{\mathrm{ON}} / \mathrm{R}_{\mathrm{AN}}$ of monoterpene $\mathrm{SOA}(3.7-4.17)$ with $\mathrm{R}_{\mathrm{AN}}\left(\mathrm{NO}^{+} / \mathrm{NO}_{2}{ }^{+}\right.$of pure ammonium nitrate) from ionization-efficiency calibration $(2.65) .{ }^{3,6-9}$ (c) To evaluate potential organic interference at $m / z 46$ in the CV-ACSM nitrate data, the CV-ACSM nitrate is corrected by the $\mathrm{CH}_{2} \mathrm{O}_{2}{ }^{+}$fragment fraction resolved using SV-AMS and then compared with SV-AMS nitrate. 

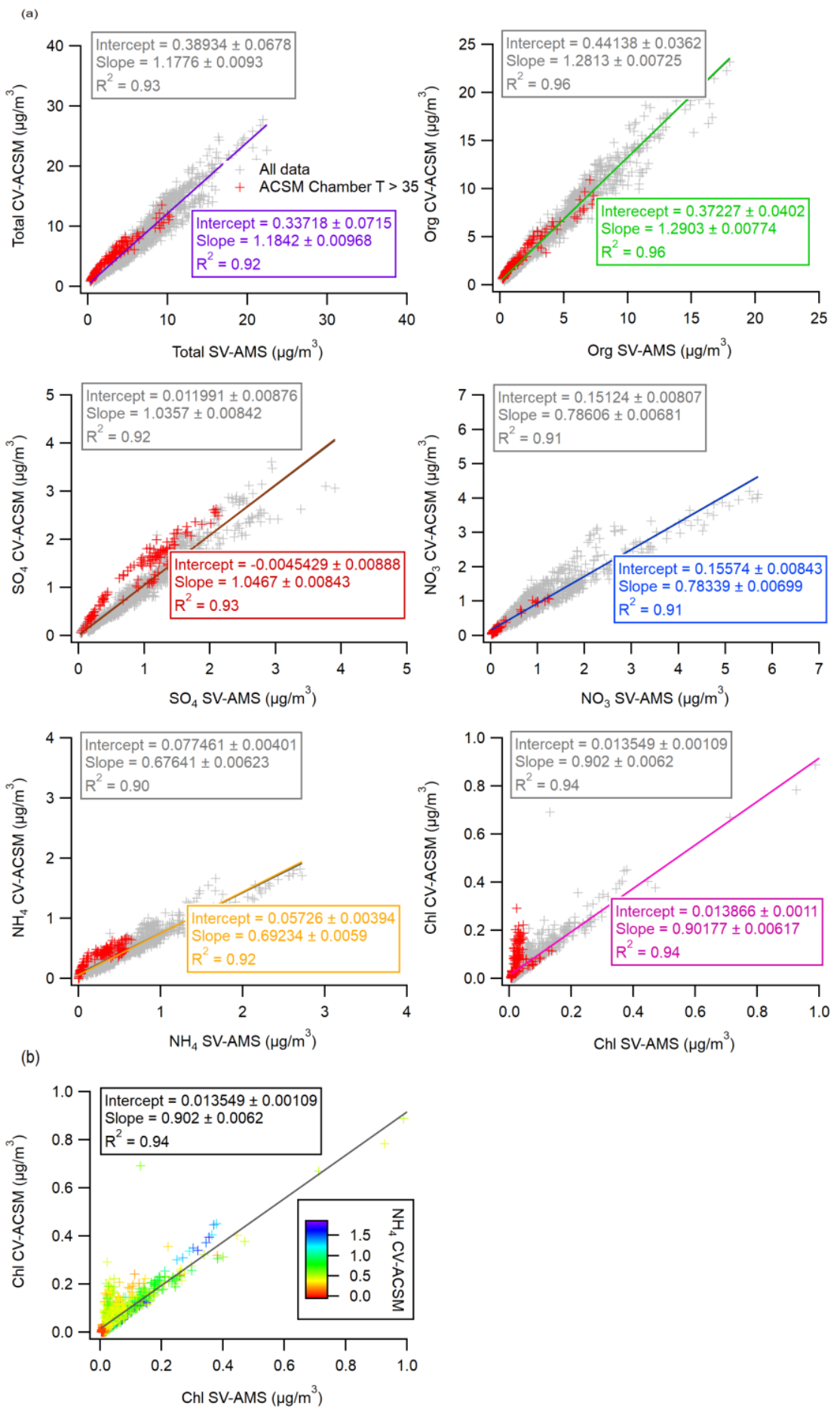

Figure S5. Comparison of species measured by CV-ACSM and SV-AMS. (a) The red-colored data points correspond to the period during ACSM chamber temperature $>35^{\circ} \mathrm{C}$. The grey fit line and equation include all data points, and colored fit line and equation corresponds to the comparison without the red-colored data points. (b) The chloride comparison is colored by $\mathrm{NH}_{4}$ measured by ACSM. As the higher chloride measured by CV-ACSM at chamber temperature $>35^{\circ} \mathrm{C}$ did not appear to correspond to higher ammonium level, this suggests that the higher chloride during this period is not in the form of $\mathrm{NH}_{4} \mathrm{Cl}$. 
(a)
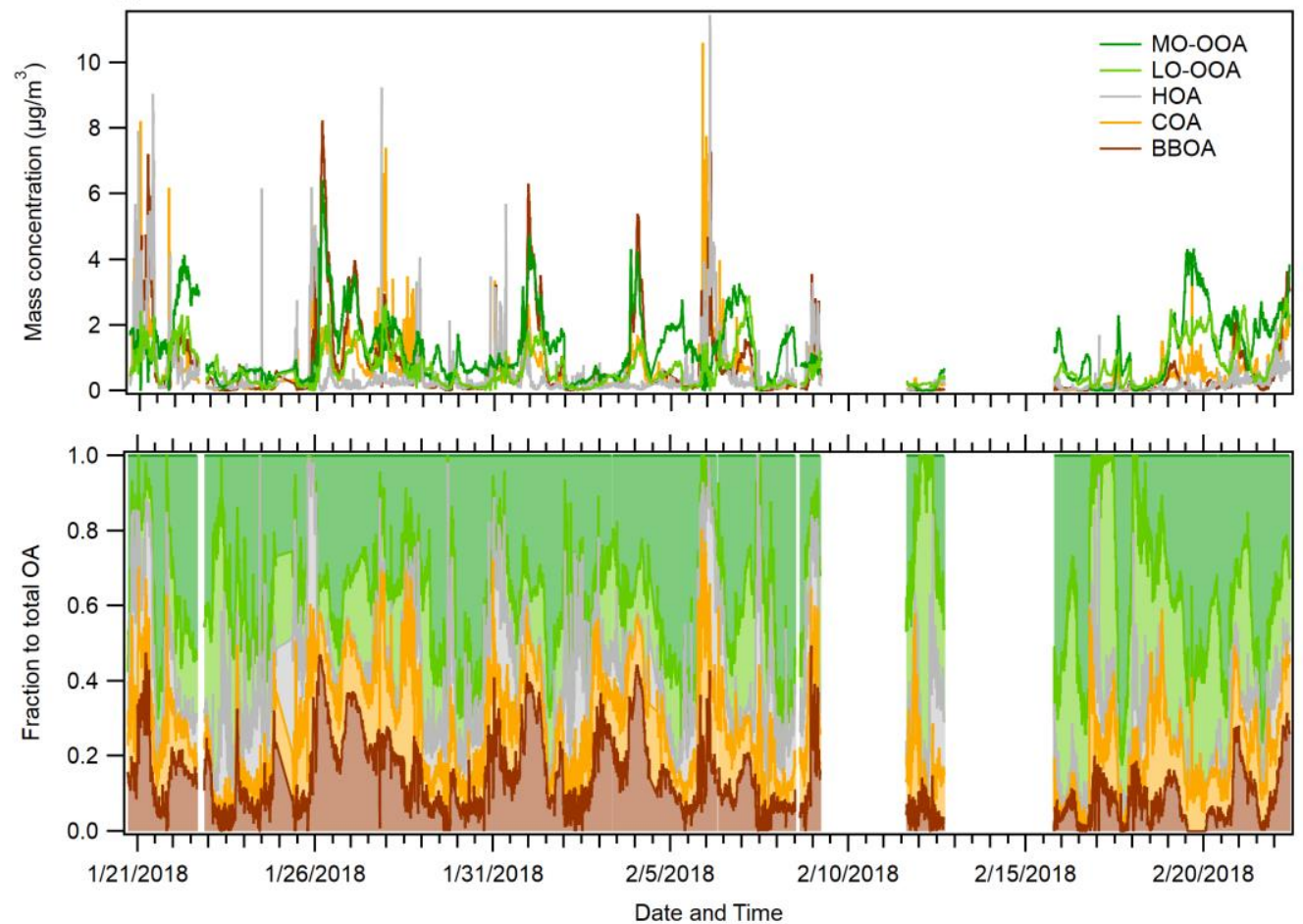

(b)
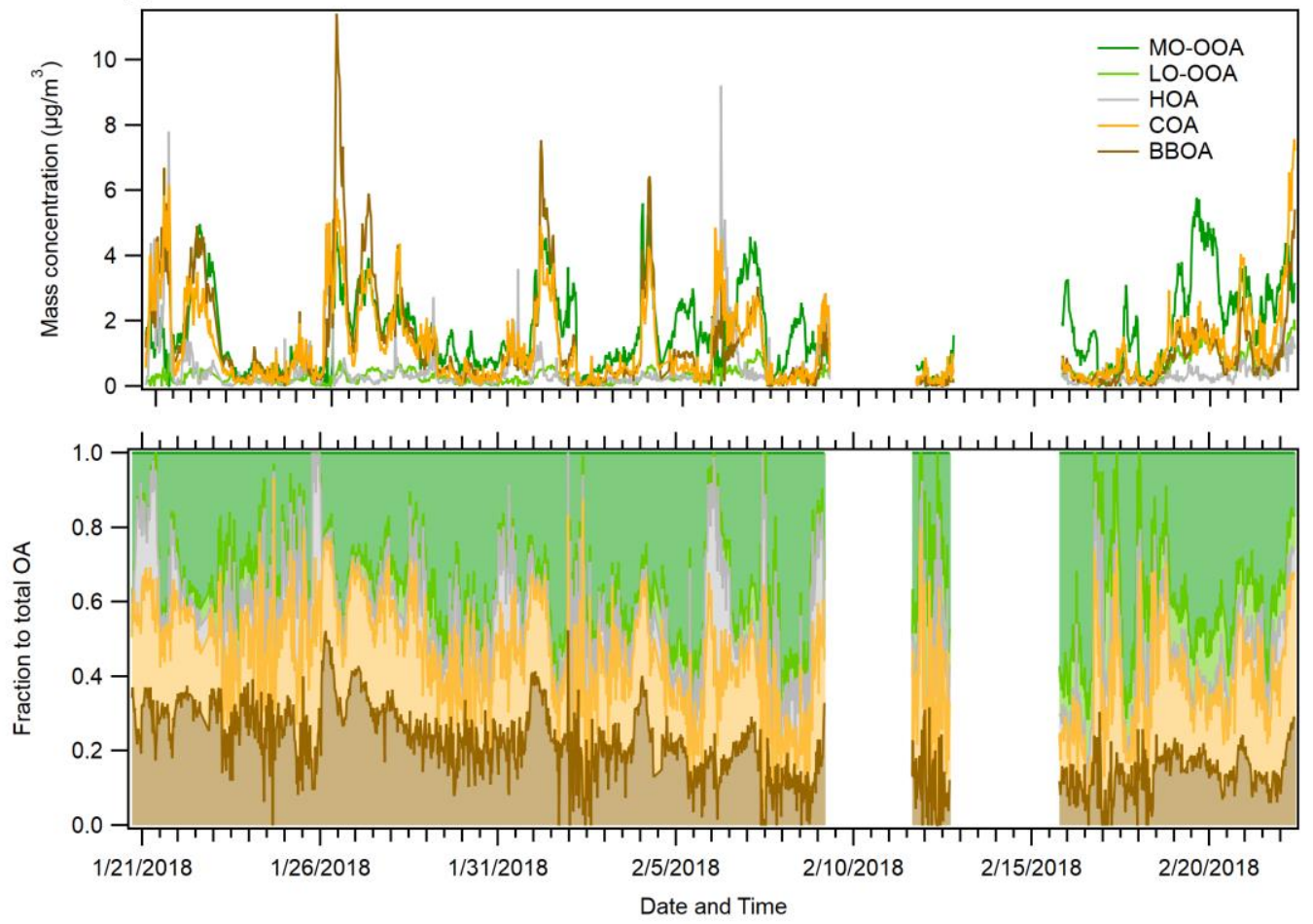

Figure S6. Mass concentration and mass fraction time series of OA factors resolved from (a) SV-AMS and (b) CV-ACSM PMF analysis. 
(a)

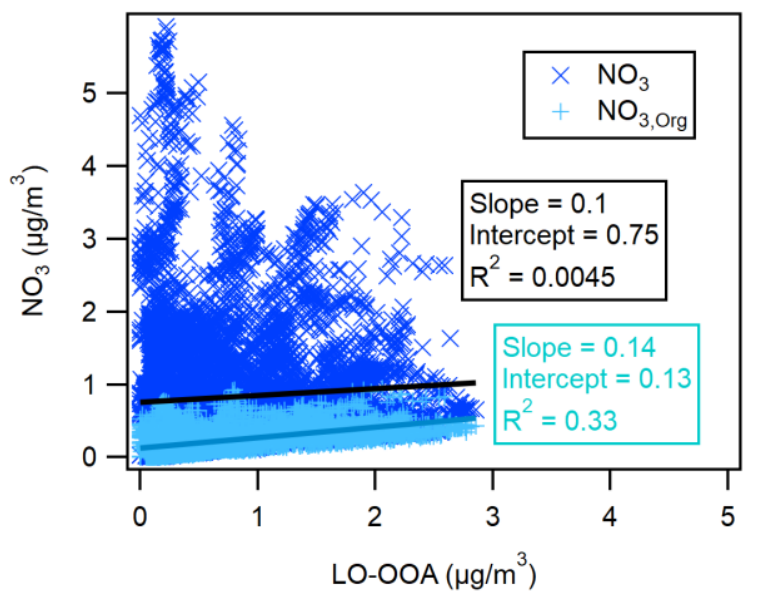

(b)

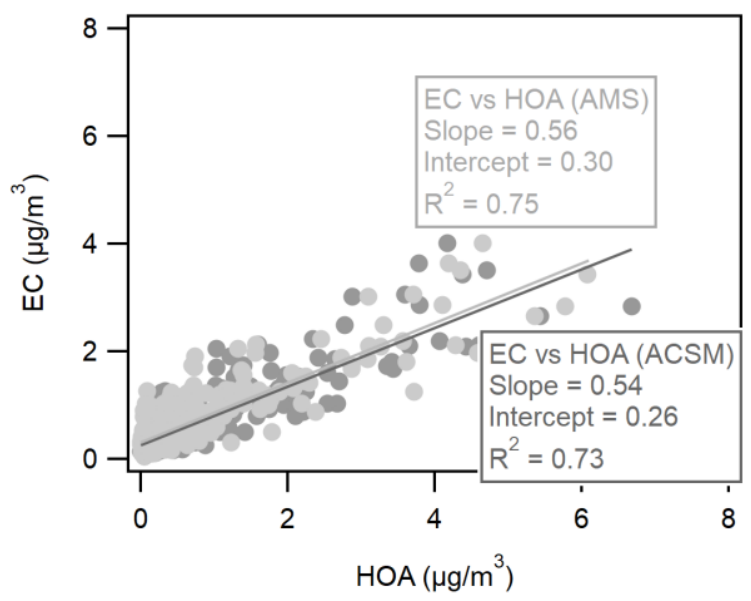

Figure S7. Comparison of PMF factors with other species. (a) SV-AMS LO-OOA is compared with AMS nitrate and $\mathrm{NO}_{3, \text { Org }}\left(\mathrm{R}_{\mathrm{ON}}=11\right) \mathrm{SV}$-AMS, and (b) CV-ACSM and SV-AMS HOA is compared with EC.

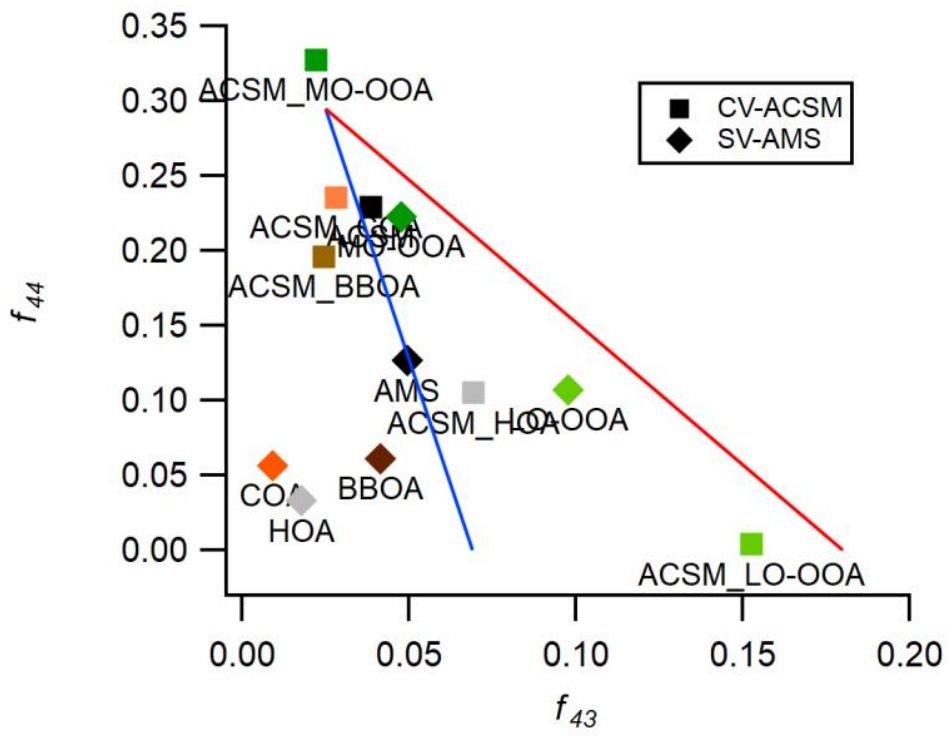

Figure S8. $f_{44}$ vs $f_{43}$ plot of OA factors resolved from PMF analysis of CV-ACSM and SV-AMS data. ${ }^{10}$ 

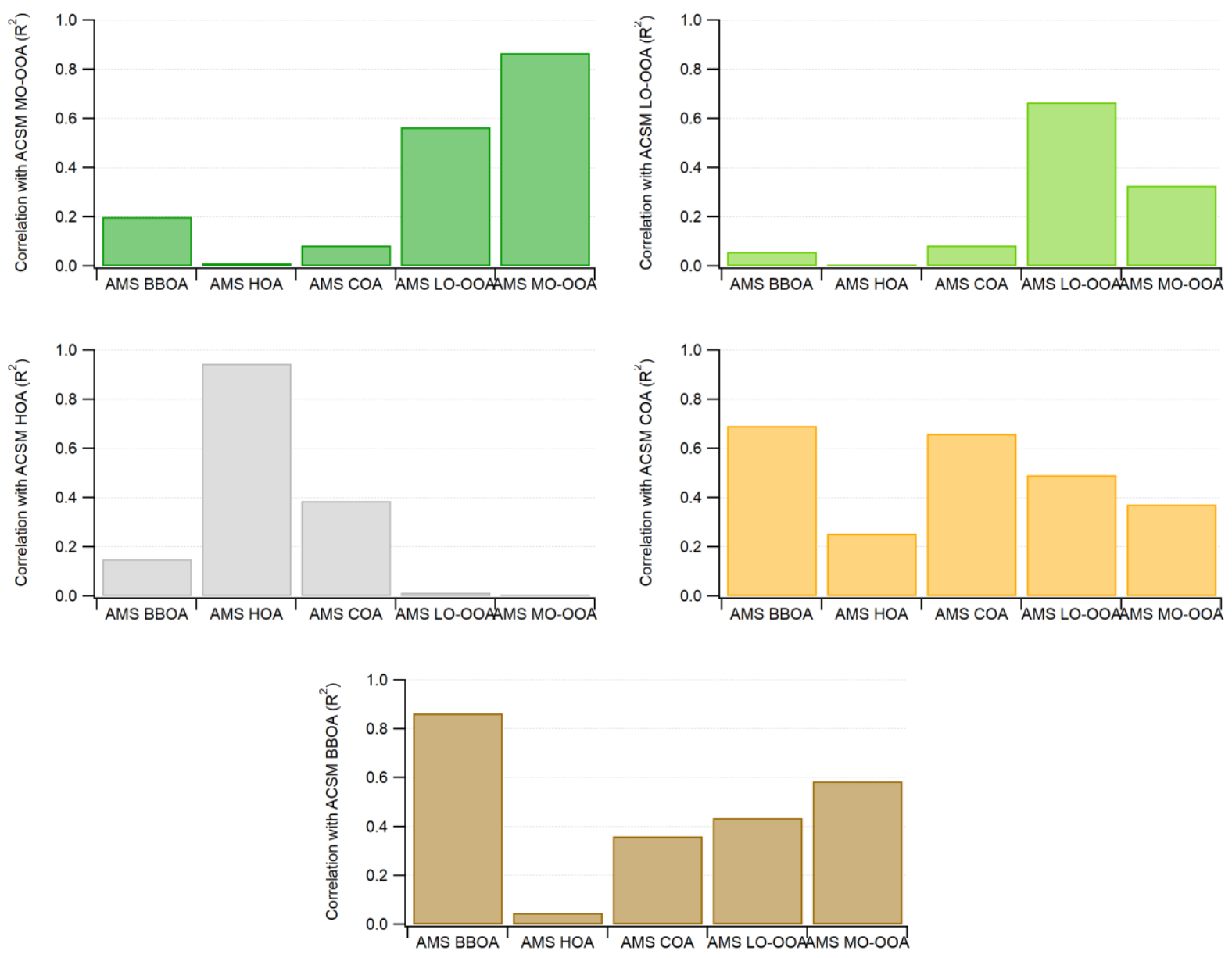

Figure S9. Coefficient of determination $\left(\mathrm{R}^{2}\right)$ between CV-ACSM PMF factors and SV-AMS PMF factors. 

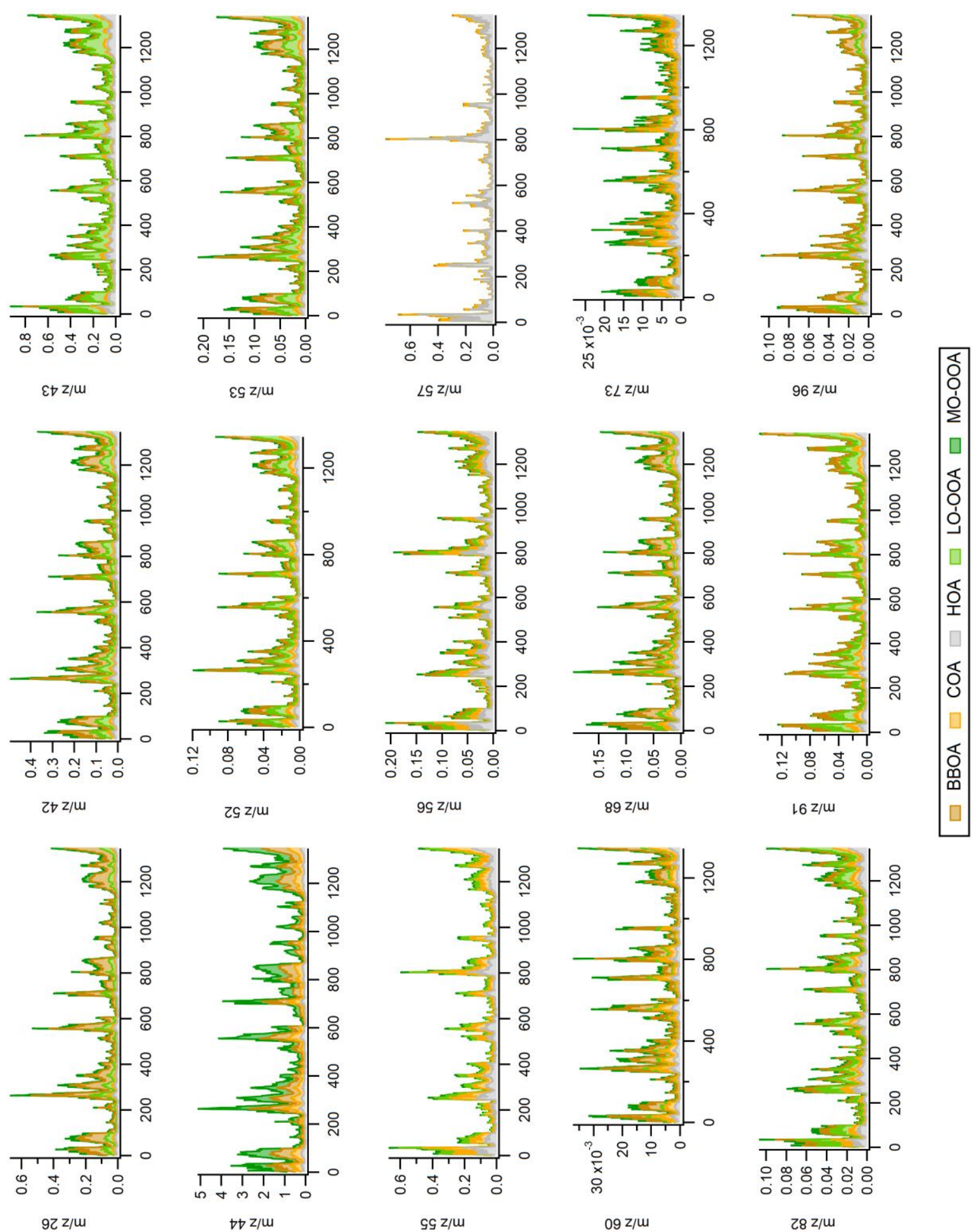

16 z/m

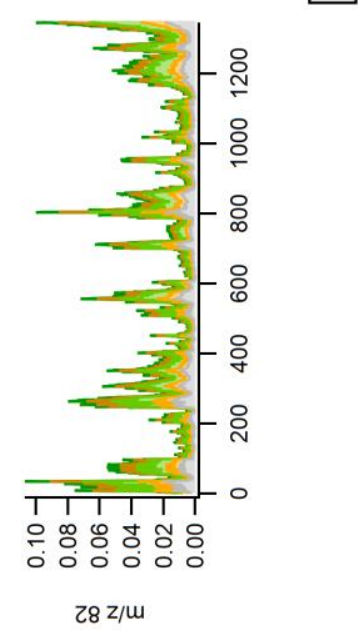

Figure S10. The contribution of each CV-ACSM OA factor in various tracer ions. 

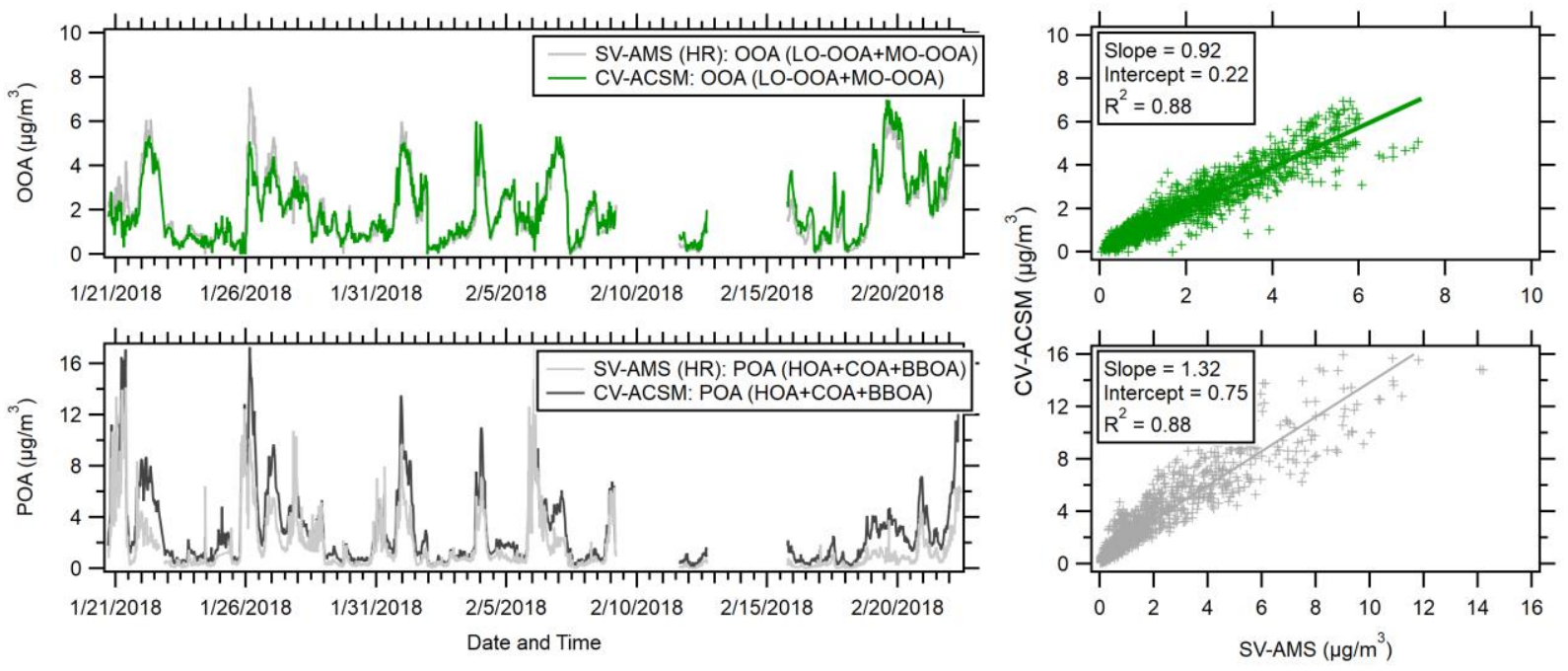

Figure S11. Comparisons of time series and scatter plots of OOA and POA factors from CV-ACSM and SV-AMS.

(a)

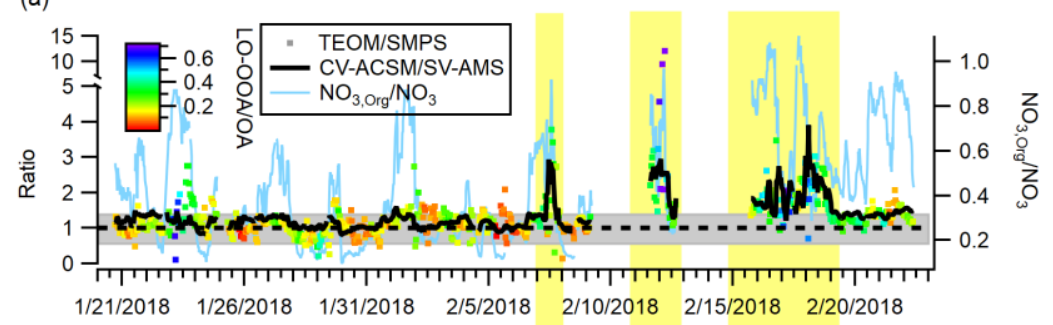

(b)

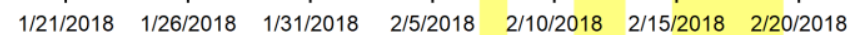
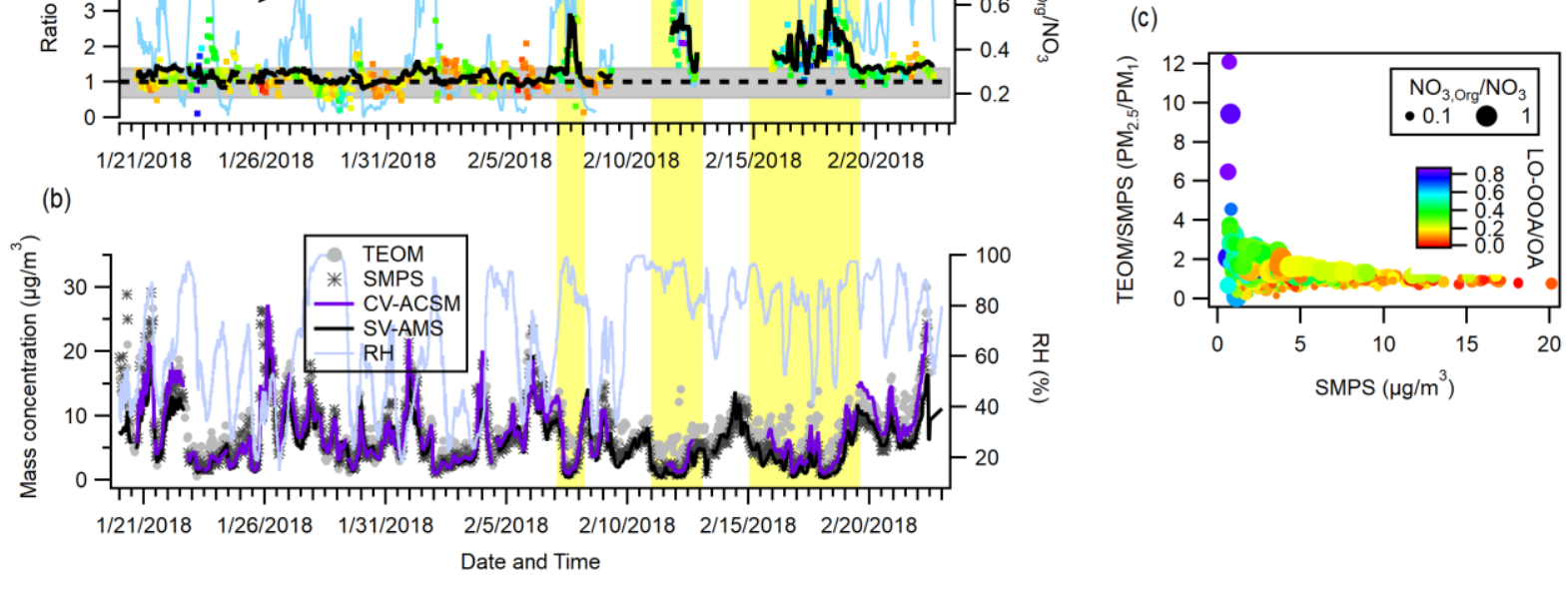

Figure S12. Time series of $(a)$ organic nitrate $\left(\mathrm{R}_{\mathrm{ON}}=11\right)$ to total nitrate ratio $(\mathrm{AMS})$, TEOM/SMPS, and ACSM/AMS ratio colored by LO-OOA/OA fraction from SV-AMS PMF analysis and (b) RH and mass concentration of TEOM PM 2.5 , SMPS PM PM $_{2.5}$-CV-ACSM, and PM $\mathrm{PM}_{1}$-SV-AMS (lower left panel). Grey region in the upper panel is the reported uncertainties in Figure S2. Yellow regions correspond to time periods when both TEOM/SMPS and CV-ACSM/SV-AMS ratios are greater than 1. (c) TEOM/SMPS ratio vs. SMPS mass concentration (data points are colored by LO-OOA/OA ratio and the marker size corresponds to $\mathrm{NO}_{3, \mathrm{Org}} /$ nitrate ratio) shows that the higher TEOM/SMPS ratio corresponds to lower aerosol loading. 
Table S1. CV-ACSM RF calibration and SV-AMS IE calibration.

\begin{tabular}{cccccc|cccc}
\hline \multicolumn{7}{c|}{ CV-ACSM } & \multicolumn{4}{c}{ SV-AMS } \\
\hline Date & $\begin{array}{c}\mathrm{NO}_{3} \mathrm{RF} \\
\left(\mathrm{x} 10^{-11}\right)\end{array}$ & $\begin{array}{c}\mathrm{N}_{2} \\
\left(\mathrm{x} 10^{-8}\right)\end{array}$ & $\begin{array}{c}\mathrm{RF} / \mathrm{N}_{2} \\
\left(\mathrm{x} 10^{-4}\right)\end{array}$ & $\begin{array}{c}\mathrm{NH}_{4} \\
\mathrm{RIE}\end{array}$ & $\begin{array}{c}\mathrm{SO}_{4} \\
\mathrm{RIE}\end{array}$ & $\mathrm{IE}$ & $\begin{array}{c}\text { Air- } \\
\text { beam } \\
\left(\mathrm{x} 10^{5}\right)\end{array}$ & $\begin{array}{c}\mathrm{NH}_{4} \\
\mathrm{RIE}\end{array}$ & $\begin{array}{c}\mathrm{SO}_{4} \\
\mathrm{RIE}\end{array}$ \\
\hline $01 / 13$ & - & - & - & - & - & 1.25 & 2.35 & 3.75 & 1.2 \\
$01 / 22$ & 4.24 & 7.67 & 5.53 & 5.65 & 1.18 & 1.25 & 2.32 & 3.85 & 1.33 \\
$02 / 04$ & 3.13 & 6.56 & 4.77 & 6.18 & 1.54 & 1.1 & 2.29 & 3.78 & 1.38 \\
$02 / 13$ & 5.27 & 9.62 & 5.48 & 5.53 & 1.4 & 1.18 & 2.30 & 3.81 & 1.32 \\
$02 / 25$ & 3.53 & 7.95 & 4.44 & 5.32 & 1.32 & 1.1 & 2.58 & 3.81 & 1.43 \\
\hline Average & $\mathbf{4 . 0 4}$ & $\mathbf{7 . 9 5}$ & $\mathbf{5 . 0 5}$ & $\mathbf{5 . 6 8}$ & $\mathbf{1 . 3 6}$ & $\mathbf{1 . 1 7 6}$ & $\mathbf{2 . 3 6}$ & $\mathbf{3 . 8}$ & $\mathbf{1 . 3 3}$ \\
\hline
\end{tabular}


1. Zhang, Q.; Jimenez, J. L.; Canagaratna, M. R.; Ulbrich, I. M.; Ng, N. L.; Worsnop, D. R.; Sun, Y., Understanding atmospheric organic aerosols via factor analysis of aerosol mass spectrometry: a review. Analytical and Bioanalytical Chemistry 2011, 401 (10), 3045-3067. 2. Xu, L.; Guo, H.; Boyd, C. M.; Klein, M.; Bougiatioti, A.; Cerully, K. M.; Hite, J. R.; 130 Isaacman-VanWertz, G.; Kreisberg, N. M.; Knote, C.; Olson, K.; Koss, A.; Goldstein, A. H.; Hering, S. V.; de Gouw, J.; Baumann, K.; Lee, S.-H.; Nenes, A.; Weber, R. J.; Ng, N. L., Effects of anthropogenic emissions on aerosol formation from isoprene and monoterpenes in the southeastern United States. Proceedings of the National Academy of Sciences 2015, 112 (1), 3742.

135 3. Xu, L.; Suresh, S.; Guo, H.; Weber, R. J.; Ng, N. L., Aerosol characterization over the southeastern United States using high-resolution aerosol mass spectrometry: spatial and seasonal variation of aerosol composition and sources with a focus on organic nitrates. Atmos. Chem. Phys. 2015, 15 (13), 7307-7336.

4. Bahreini, R.; Ervens, B.; Middlebrook, A. M.; Warneke, C.; de Gouw, J. A.; DeCarlo, 140 P. F.; Jimenez, J. L.; Brock, C. A.; Neuman, J. A.; Ryerson, T. B.; Stark, H.; Atlas, E.; Brioude, J.; Fried, A.; Holloway, J. S.; Peischl, J.; Richter, D.; Walega, J.; Weibring, P.; Wollny, A. G., et al., Organic aerosol formation in urban and industrial plumes near Houston and Dallas, Texas. Journal of Geophysical Research: Atmospheres 2009, 114 (D7).

5. Hu, W.; Campuzano-Jost, P.; Day, D. A.; Croteau, P.; Canagaratna, M. R.; Jayne, J.

145 T.; Worsnop, D. R.; Jimenez, J. L., Evaluation of the new capture vaporizer for aerosol mass spectrometers (AMS) through field studies of inorganic species. Aerosol Science and Technology 2017, $51(6), 735-754$. 
6. Farmer, D. K.; Matsunaga, A.; Docherty, K. S.; Surratt, J. D.; Seinfeld, J. H.;

Ziemann, P. J.; Jimenez, J. L., Response of an aerosol mass spectrometer to organonitrates and 150 organosulfates and implications for atmospheric chemistry. Proceedings of the National Academy of Sciences 2010, 107 (15), 6670-6675.

7. Boyd, C.; Sanchez, J.; Xu, L.; Eugene, A. J.; Nah, T.; Tuet, W.; Guzman, M. I.; Ng, N., Secondary organic aerosol formation from the $\beta$-pinene+ NO 3 system: effect of humidity and peroxy radical fate. Atmospheric Chemistry and Physics 2015, 15 (13), 7497-7522.

155 8. Bruns, E. A.; Perraud, V.; Zelenyuk, A.; Ezell, M. J.; Johnson, S. N.; Yu, Y.; Imre, D.; Finlayson-Pitts, B. J.; Alexander, M. L., Comparison of FTIR and Particle Mass Spectrometry for the Measurement of Particulate Organic Nitrates. Environmental Science \& Technology 2010, 44 (3), 1056-1061.

9. Fry, J. L.; Kiendler-Scharr, A.; Rollins, A. W.; Wooldridge, P. J.; Brown, S. S.; Fuchs, 160 H.; Dubé, W.; Mensah, A.; dal Maso, M.; Tillmann, R.; Dorn, H. P.; Brauers, T.; Cohen, R. C., Organic nitrate and secondary organic aerosol yield from $\mathrm{NO}<\mathrm{sub}>3</$ sub $>$ oxidation of $\beta$ pinene evaluated using a gas-phase kinetics/aerosol partitioning model. Atmos. Chem. Phys. 2009, 9 (4), 1431-1449.

10. Ng, N. L.; Canagaratna, M. R.; Jimenez, J. L.; Chhabra, P. S.; Seinfeld, J. H.;

165 Worsnop, D. R., Changes in organic aerosol composition with aging inferred from aerosol mass spectra. Atmos. Chem. Phys. 2011, 11 (13), 6465-6474. 